\title{
CANINDE-IOUNE: REPERTÓRIO DE MATRIZ INDÍGENA E AFRICANA EM CANCIONEIRO PARA AULAS DE CANTO ORFEÔNICO
}

\author{
Inês de Almeida Rocha \\ Colégio Pedro II/PPGM-UNIRIO \\ ines.rocha2006@hotmail.com
}

\begin{abstract}
RESUMO
O objetivo do artigo é analisar o processo de publicação e o repertório do cancioneiro Guia Prático: estudo folclórico musical, de Heitor Villa-Lobos, observando como o uso de elementos identificados nas canções de matrizes indígena, africana e europeia, revelam diversidade musical, concepções educativas e sociais do período que foram compostas. A análise se apoia em premissas estudadas pela História da Cultura Escrita, no que se refere à produção, apropriação e circulação da cultura escrita e em estudos sobre História da Educação Musical. A análise demonstrou que, $m$ esmo com um discurso de valorização da cultura autóctone, rural e afrodescendente, a lógica hierárquica europeia estava consolidada e reforçada pela hegemonia dos elementos da música clássica ocidental.
\end{abstract}

Palavras-chave: Patrimônio e História da Educação Musical. Diversidade cultural. Manuais escolares de música.

\section{CANINDE-IOUNE: REPERTORIO DE MATRIZ INDÍGENA Y AFRICANA EN CANCIONERO PARA CLASES DE CANTO ORPHEÓNICO}

\section{RESUMEN}

El objetivo del artículo es analizar el proceso de publicación y el repertorio del cancionero Guia Prático: estudo folclórico musical, de Heitor Villa-Lobos, observando cómo el uso de elementos identificados en los cantos de matrices indígenas, africanas y europeas, revelan diversidad concepciones musicales, aspectos educativos y sociales del período que fueron compuestos. El análisis se basa en premisas estudiadas por la Historia de la Cultura Escrita, en cuanto a la producción, apropriación y circulación de la cultura escrita y autores de la Historia de la Educación Musical. El análisis mostró que, incluso con un discurso de valoración de la lógica jerárquica europea se consolidó y reforzó con la hegemonía de los elementos de la música clásica occidental.

Palavras clave: Patrimonio e Historia de la Educación Musical. Diversidad cultural. Manuales de música escolar.

\section{CANINDE-IOUNE: REPERTOIRE OF INDIGENOUS AND AFRICAN MATRIX IN SONGBOOK FOR ORPHEONIC SINGING CLASSES}

\begin{abstract}
The objetive of the article is to analyse the publication process and the repertoire of the songbook Guia Prático: estudo folclórico musical, de Heitor Villa-Lobos, observing how the use of elements identified in the songs of indigenous, African and European matrices, reveal musical diversity, conceptions educational and social aspects of the period that were composed. The analysis is based on premises studied by the History of Written Culture, in terms of the
\end{abstract}


production, appropiation and circulation of written culture and authors of the History of Musical Education. The analysis showed that, even with a discourse of valuing indigenous, rural and Afro-decendant culture, the European hierarchical logic was consolidated and reinforced by the hegemony of the elements of Western classical music.

Keywords: Heritage and History of Music Education. Cultural diversity. School music manuals.

\title{
CANINDE-IOUNE: REPERTOIRE DE MATRICE INDIGENE ET AFRICAINE DANS LE RECUEIL DE CHANSONS POUR LES COURS DE CHANT ORPHONIQUE
}

\author{
RÉSUMÉ
}

Le but de l'article est d'analyser le processus de publication et le répertoire du recuel de chansons Guia Prático: estudo folclórico musical, de Heitor Villa-Lobos, en observant comment l'utilisation des éléments identifiés dans les chansons des matrices autochtones, africaines et européennes, révèle la diversité musicale, les conceptions aspects éducatifs et sociaux de la période qui ont été comprsées. L'analyse s'appuie sur des prémisses étudiées par l'Histoire de la culture écrite, en termes de production, d'appropriation et de circulation de la culture écrite et des auteurs de l'Histoire de l'éducation musicale. L'analyse a montré que, même avec un discours de valorisation de la culture indigène, rurale et afro-descendante, la logique hiérarchique européenne était consolidée et renforncée par l'hégémonie des éléments de la musique classique occidentale.

Mots clés: Patrimoine et histoire de l'enseignement musical. Diversité culturelle. Manuels de musique scolaires.

\section{INTRODUÇÃO}

Este texto analisa o livro Guia Prático: estudo folclórico musical, um importante cancioneiro brasileiro, observando o uso de melodias e elementos musicais identificados nas músicas de matrizes indígena, africana e europeia e o processo de composição da obra ${ }^{1}$.

A pesquisa, de cunho bibliográfico e com enfoque musicológico e histórico social, objetiva analisar concepções de diversidade musical e valores educativos e sociais, que circulavam no período em que as canções foram compostas e utilizadas, para refletir sobre como elementos de matriz indígena e africana foram utilizados no projeto idealizado pelo compositor

\footnotetext{
${ }^{1}$ Este texto é produção acadêmica vinculada à pesquisa "ESTUDARAM AQUI, BRASILEIROS DE UM ENORME E SUBIDO VALOR”: cultura material e manuais escolares no Colégio Pedro II, cadastrada e desenvolvida nessa instituição com participação de bolsistas de Iniciação Científica, estudantes do Ensino Fundamental e Ensino Médio. A investigação vem acolhendo projetos em diferentes níveis e tem como objetivo analisar as práticas de educação musical, refletindo sobre diversos aspectos que se pode depreender dos manuais escolares, papéis, cadernos e objetos, enfim a cultura material, pertencente ao acervo de Educação Musical do Campus Centro do Colégio Pedro II.
} 
Heitor Villa-Lobos para o cancioneiro conhecido como Guia Prático, destinado ao projeto educativo musical Canto Orfeônico liderado por ele a partir da década de 1930 no Brasil.

A análise se apoia, também, nos três planos propostos por António Castillo Gómez para análise de produção textual, a saber, análise dos discursos, das práticas e das representações (CASTILLO GÓMEZ, 2003a, 2004). Para o estudo de produções escritas, há que considerar "la teoría del escrito, la práctica del escribir y la sociedad que escribe o consume lo escrito" (CASTILLO GÓMEZ, 2003b, p. 15)².

Em outras palavras, Castillo Gómez (2004) diz:

Su estudio debe atender a las consecuencias sociales y culturales derivadas de su implantación y extensión: así como a la incidencia de aquellas en las formas, funciones y usos de lo escrito, en los mecanismos y lugares de adquisición, en las redes de sociabilidad de escribientes y analfabetos, en las políticas de la escritura y del escribir, en los modos de circulación y a apropiación, o en las maneras, tipologías y espacios de la lectura. (CASTILLO GÓMEZ, 2004, p. 90). ${ }^{3}$

A partir desses pressupostos teóricos, apoiaremos a análise neste texto. Muito embora essa proposta tenha sido pensada para análise da cultura escrita da linguagem verbal, consideramos possível a aplicação desses constructos para a análise textual musical, principalmente ao considerar os elementos de textos verbais quando combinados com alguns elementos específicos da linguagem musical, ou, em outras palavras, elementos textuais verbais utilizados em elementos textuais musicais ${ }^{4}$. Ressalto, também, que a análise terá ênfase em aspectos relacionados a questões que se inserem no campo da História da Educação Musical e de Patrimônio Educativo. Não serão aprofundados, elementos de análise da linguagem musical mais específicos, dado o contexto no qual a pesquisa está sendo apresentada, ou seja, um periódico no qual pesquisadores que estudam, sob diversos olhares, o Patrimônio Educativo e não um grupo que se dedica a especificidades que a área da Música tem se ocupado até o momento.

A publicação musical aqui analisada, constitui a obra mais conhecida e divulgada como livro base de canto orfeônico, composta e organizada por Heitor Villa-Lobos para o

\footnotetext{
2 "A teoria do escrito, a prática de escrever e a sociedade que escreve e consume o escrito."

3 "Seu estudo deve atender às consequências sociais e culturais derivadas de sua implantação e extensão: assim como sobre a incidência daquelas nas formas, funções e usos do escrito, nos mecanismos e lugares de aquisição, nas redes de sociabilidade dos que escreviam e dos analfabetos, nas políticas da escrita e do escrever, nos modos de circulação e a apropriação, ou nas maneiras, tipologias e espaços da leitura"

${ }^{4}$ Texto musical no presente artigo será considerado como a partitura, mais especificamente, a partitura impressa. Ressalto, contudo, minha concordância com outros estudiosos que consideram texto musical uma gravação em diferentes suportes, uma performance, um manuscrito ou um impresso em variadas tecnologias (NOGUEIRA, 2009, p. 27).
} 
projeto educativo sob sua coordenação e direção de implementação a partir de 1931 nas escolas brasileiras. Essa publicação evidencia a memória das práticas musicais e escolares, podendo ser entendida como um documento-monumento, na concepção do historiador Jacques Le Goff, na qual um documento é depositário de memória, história, valores e concepções de um tempo. (LE GOFF, 1992). Sendo assim, analisar publicações legitimadas por comunidades escolares e acadêmicas, oferece possibilidades consistentes para ampliarmos a compreensão sobre as práticas musicais escolares, sobre concepções musicais de um período temporal e sobre a história da música de um grupo social, geograficamente situado e o patrimônio cultural e educativo legitimado.

\section{O CANTO ORFEÔNICO E O INCREMENTO DE PUBLICAÇÕES DE PARTITURAS E DE MANUAIS ESCOLARES DE MÚSICA}

Em 1931, durante o governo do presidente Getúlio Vargas, Anísio Teixeira esteve à frente de uma reforma do sistema educacional brasileiro e acolheu o projeto pedagógico musical do compositor Heitor Villa-Lobos denominado Canto Orfeônico. Foi criada para a implementação desse projeto, a Superintendência de Educação Musical e Artística (SEMA). Um dos pilares do Canto Orfeônico consistia na prática vocal em conjunto em uníssono ou várias vozes. Essa prática vocal nas escolas brasileiras já existia, em maior ou menor grau, dependendo da região do país, inclusive com a ênfase em repertório com canções patrióticas e/ou religiosas. Porém a estrutura governamental e os investimentos financeiros que apoiaram o projeto de Villa-Lobos foi algo inédito, de grandes proporções, e provavelmente, único no Brasil (FUKS, 1991).

Além do órgão governamental criado para sustentar a implantação e implementação do projeto, no mesmo ano, iniciam os cursos emergenciais para formação de professores (Cursos de Pedagogia da Música e Canto Orfeônico). Em 1942, criou-se o Conservatório Nacional de Canto Orfeônico (CNCO), incorporado, posteriormente à Universidade Federal do Estado do Rio de Janeiro (TACUCHIAN, 2009, p. 8).

Milhares de Orfeões Escolares ${ }^{5}$ surgiram pelo país, fazendo a juventude cantar em grupo canções folclóricas, patrióticas e populares. Vasta literatura musical e pedagógica foi publicada e utilizada por professores e alunos, fomentando o comércio e a produção de partituras e livros de música. Musicistas e professores dedicaram-se à publicação de obras

\footnotetext{
${ }^{5}$ Orfeão Escolar, ou Orfeão, foram denominações utilizada para os grupos escolares de canto coletivo a uma, duas, três ou quatro vozes formado em escolas, com especial ênfase durante o período das décadas de 1930, 1940 e 1950 e parte da década de 1960, quando o projeto do Canto Orfeônico de Villa-Lobos aconteceu em seu apogeu.
} 
didáticas para as aulas de canto orfeônico, seja em forma de partituras ou de manuais escolares para alunos e para professores, movimentando grandes cifras de dinheiro pelas editoras especializadas em obras educativas e musicais (ROCHA, 2012). Dentre os autores, muitas mulheres vislumbraram a possiblidade de legitimarem suas carreiras profissionais, publicando livros nesse período (IGUAYARA-SOUZA, 2011) ${ }^{6}$. Na década de 1930, na Europa, compositores também dedicaram esforços quanto à produção intensa de música funcional, ou Gebrauschsmusik, ou música de uso, como Paul Hindemith, Darius Milhaud, Zoltan Kodaly, Carl Orff, Bela Bartok, dentre outros. Essas obras tinham finalidades pedagógicas diferenciadas (para o ensino instrumental, para ensino de música em escolas, para iniciação musical de crianças, etc.) e graus diferenciados de complexidades técnicas e expressivomusicais (LAGO; BARBOSA; BARBOSA, 2009, p. 18).

O Guia Prático, por suas características múltiplas, pode ser compreendido como um cancioneiro infanto-juvenil, ou seja, um conjunto de canções destinada para crianças e jovens, mas também como um manual escolar, um livro didático, e não apenas uma coletânea de partituras corais. As músicas e arranjos corais foram elaborados com um objetivo pedagógico musical, para utilização de professores e alunos nas aulas e para ser cantado pelos orfeões escolares e pelo Orfeão de Professores, esse último dirigido pelo próprio maestro Villa-Lobos. Cantando em conjunto o repertório específico e planejado, os alunos ampliariam seus conhecimentos, habilidades musicais e, como acreditaram os protagonistas desse projeto, desenvolveriam sentimentos cívicos e de amor à Pátria natal.

Essa prática de canto coletivo, agregava valores estéticos, reflexo do movimento modernista que teve a Semana de Arte de 1922 em São Paulo como ponto emblemático. VillaLobos e muitos de seus colaboradores estiveram sintonizados em suas ações com as rupturas estéticas propostas por esse movimento (FUKS. 1991). Agregou-se também, um viés ideológico nacionalista que caracterizou as práticas pedagógicas e musicais vinculadas ao projeto e a partir de sua implementação nas escolas, seja no que se refere às concepções estéticas, mas também políticas, especialmente após a decretação do Estado Novo, a partir de 1937. Com o apoio governamental e acolhimento institucional do conjunto de ações produzidas por esse projeto, formou-se um grupo de músicos e educadores em torno da proposta

\footnotetext{
${ }^{6}$ Para saber mais sobre publicação de livros didáticos escritos por professoras de canto orfeônico, ver: IGAYARASOUZA, Susana Cecilia. Entre palcos e páginas: a produção escrita por mulheres sobre música na história da educação musical no Brasil (1907-1958). Tese (Doutorado em Educação). São Paulo: FEUSP, 2011.
} 
villalobiana com grande capital político, musical e pedagógico, o que viabilizou muitas ações que expandiram as práticas orfeônicas em escolas de várias regiões do Brasil.

Em 1942, Heitor Villa-Lobos deixou a liderança do projeto e passou a dedicar-se à sua carreira de compositor e maestro.

\section{O GUIA PRÁTICO E O PLANEJAMENTO DE SEIS VOLUMES DA OBRA}

Uma das importantes publicações utilizadas nas aulas de canto orfeônico no período inicial de implementação do projeto de Villa-Lobos foi a Coleção Escolar, fascículos individuais que continham partituras corais para serem utilizadas nas escolas, publicados entre 1932 e 1936, pela Casa Arthur Napoleão - Sampaio Araújo e pelo Departamento de Educação do Distrito Federal. Em 1937, o compositor publicou o último fascículo dessa coleção: $O$ ensino popular da música no Brasil: o ensino da música e do canto orfeônico nas escolas, com um anexo, Índice e quadro sinótico", ambos compondo uma espécie de fundamentação teórica para as partituras (LAGO; BARBOSA; BARBOSA, 2009, p. 18). Observa-se que muitos fascículos dessa coleção inicial foram republicados em outras coletâneas e que, em suma, esses fascículos eram parte de um projeto mais ambicioso, contendo repertório a ser utilizado nas aulas de canto orfeônico das escolas de todas as regiões do país.

Em 1940, alguns dos fascículos individuais da Coleção Escolar já publicados e em circulação, foram reunidos em um volume único: o Guia Prático: estudo folclórico musical, publicado pela Irmãos Vitale e Mangione ${ }^{7}$. É possível considerar, no entanto que, durante um determinado período coexistiram "publicações distintas do Guia Prático, nas iniciais versões individuais em fascículos (Departamento de Educação do Distrito Federal e Arthur NapoleãoSampaio Araújo) e em volume único (Irmãos Vitale e Mangione)" (LAGO; BARBOSA; BARBOSA, 2009, p. 44). Apesar da coleção inicial ter sido constituída por 250 músicas, apenas 137 canções foram reunidas no primeiro e único volume do Guia Prático efetivamente concretizado dentre os seis volumes idealizados para esse projeto. Muito provavelmente as canções que não entraram nesse volume se enquadrariam no planejamento dos demais volumes. É o que veremos a seguir.

Lago, Barbosa e Barbosa, que revisitam e comparam várias edições desse livro, em criterioso projeto de reedição da obra, referem-se assim sobre esse volume único, considerando as peças

\footnotetext{
${ }^{7}$ Villa-Lobos editou, também, as peças do Guia Prático $1^{\circ}$. Volume), para piano na coleção Guia Prático - Álbuns para Piano.
} 
[...] apresentam, como característica comum, sua destinação ao canto orfeônico. Entretanto, elas constituem um conjunto heterogêneo, fortemente diferenciado quanto ao escopo, o grau de complexidade, e as modalidades de execução (vocal e instrumental. As 137 peças se repartem entre 58 peças $a$ cappella, de uma a quatro vozes, e 79 peças para coro, de uma a três vozes, com acompanhamento instrumental. (LAGO; BARBOSA; BARBOSA, 2009, p. 18).

O projeto do Guia Prático, no entanto, havia sido pensado como um conjunto de seis volumes. No prefácio da edição publicada pela Editora Irmãos Vitale em 1941, constante no Acervo de Educação Musical do Campus Centro do Colégio Pedro II, no qual estamos pesquisando, Villa-Lobos expôs, no seguinte quadro, o projeto para os volumes da coletânea ${ }^{8}$.

Quadro 1: plano dos volumes concebidos para a coletânea que constituiria Guia Prático.

\begin{tabular}{|l|l|l|}
\hline $1^{\circ}$. Volume & Recreativo Musical & $\begin{array}{l}137 \text { cantigas infantis populares, cantadas pelas } \\
\text { crianças brasileiras, e cânticos e canções }\end{array}$ \\
\hline $2^{\circ}$. Volume & Cívico Musical & $\begin{array}{l}\text { Hinos nacionais e estrangeiros; canções } \\
\text { escolares e patrióticas }\end{array}$ \\
\hline $3^{\circ}$. Volume & Recreativo Artístico & Canções escolares nacionais e estrangeiras \\
\hline $4^{\circ}$. Volume & Folclórico Musical & $\begin{array}{l}\text { Temas ameríndios, mestiços, africanos, } \\
\text { americanos e temas populares universais }\end{array}$ \\
\hline $5^{\circ}$. Volume & Livre escolha dos alunos & $\begin{array}{l}\text { Músicas selecionadas com o fim de permitir a } \\
\text { observação do progresso, da tendência e gosto } \\
\text { artístico, revelados na escolha feita pelo aluno, } \\
\text { das músicas adotadas para este gênero de } \\
\text { educação }\end{array}$ \\
\hline $6^{\circ}$. Volume & Artístico Musical & $\begin{array}{l}\text { Litúrgica e profana, estrangeiras, nacionais, } \\
\text { gêneros acessíveis }\end{array}$ \\
\hline
\end{tabular}

Fonte: Villa-Lobos (2009).

A proposta não foi concluída e constou apenas o primeiro volume, com 137 canções já publicadas em fascículos na Coleção Escolar. Há que considerar a saída de Villa-Lobos à frente do SEMA em 1942 como um dos motivos de desarticulação do projeto. Em 2009, a Academia Brasileira de Música e a FUNARTE, publicaram nova edição revisada e comentada, constando alguns acréscimos e reordenamento as mesmas 137 canções e o mesmo conteúdo daquele volume único, em uma edição atualizada, distribuída em quatro volumes. Os editores optaram por uma reorganização também da ordem de publicação das canções pelos novos volumes, substituindo a ordem alfabética dos títulos das canções (critério adotado por VillaLobos), seguindo "um reordenamento dessas peças, a partir de suas características de execução" (seja reordenando e reunindo peças para coro a cappella, seja separando e reordenando as peças para coro com acompanhamento instrumental) (LAGO; BARBOSA; BARBOSA, 2009, p. 18).

\footnotetext{
${ }^{8}$ Na edição de 2009, consta informação que esse quadro já aparece na edição de 1940.
} 
Em pesquisa realizada por Rosa Fuks, entre 1991 e $1993^{9}$, da qual participamos como bolsista (CNPQ), foi possível examinar o manuscrito do primeiro volume publicado do Guia Prático. O manuscrito encontrado na Divisão de Música e Arquivo Sonoro da Fundação Biblioteca Nacional (DIMAS-BN) oferece evidências da possibilidade de que as composições musicais fossem fruto de uma escrita coletiva, pois foram observados tipos diferentes de caligrafia musical, cores, texturas e tintas de variados tipos - talvez pela utilização de diversos objetos de escrita- e anotações verbais que desafiam um retorno a esse manuscrito arquivado, pensando na possível participação de outros músicos e de integrantes do SEMA na versão final para a impressão desse conjunto de obras corais.

A edição do Guia Prático de 2009, um projeto de reorganização coletiva, agrega novos significados à obra, pois há importantes informações decorrentes do trabalho musicológico e de análise empreendida pelos editores ao compararem diversas versões impressas e manuscritas, além de outras coleções para canto orfeônico com autoria de Villa-Lobos (LAGO; BARBOSA; BARBOSA, 2009, p. 17). Ao relacionar o conteúdo desse quadro com outras publicações do compositor esses pesquisadores constaram que algumas obras publicadas em outras coleções têm as características descritas no quadro acima. É possível inferir que tenham sido compostas para os volumes subsequentes e aproveitadas em outras coletâneas. Vejamos algumas possibilidades para as propostas expressas no quadro para os volumes 2 a 6 .

O que Villa-Lobos descreve para o $2^{\circ}$. volume (Cívico Musical: hinos nacionais e estrangeiros, canções escolares e patrióticas) foi publicado nas coleções Canto orfeônico I e II e Solfejos II (LAGO; BARBOSA; BARBOSA, 2009, p. 44). Essas três coleções (Canto Orfeônico e Solfejos) foram amplamente utilizadas pelos professores nas escolas, o que pode ser observado no repertório utilizado nas apresentações musicais escolares, cívicas. Um dos principais eventos organizado pelas escolas eram denominados de Concentrações Orfeônicas, que eram acontecimentos de grande porte reunindo alunos, professores, músicos e diferentes profissionais para canto coletivo, no qual as músicas com teor nacionalista e cívico eram predominantes.

Para o $3^{\circ}$. volume (Recreativo Artístico: canções escolares nacionais e estrangeiras), também proveniente de peças da Coleção Escolar, observa-se em diversas partituras impressas a indicação Guia Prático - 3º volume. É o caso de Gaturamo, Canarinho, Tico-tico, Repiu-piu-

\footnotetext{
${ }^{9}$ Projeto intitulado "Prática Musical da Escola Normal: dos seus primórdios no Brasil aos anos 30", financiado pelo CNPq, realizado entre 1991 e 1993.
} 
piu, Minha terra tem palmeiras, Infância, também incluídas nas publicações Canto orfeônico I e II (LAGO; BARBOSA; BARBOSA, 2009, p. 44).

O volume 5 previa "Livre Escolha dos Alunos: músicas selecionadas com o fim de permitir a observação do progresso, da tendência e gosto artístico, revelados na escolha feita pelo aluno, das músicas adotadas para este gênero de educação”. Essa é uma descrição instigadora. Teria um caráter avaliativo para indicar resultados do projeto, ou que possibilidades podemos inferir? Em busca de uma possível resposta, há que considerar que Villa-Lobos estava vinculado a um órgão no qual participavam vários signatários do Manifesto dos Pioneiros ${ }^{10}$, dentre eles Anísio Teixeira (MONTI, 2015). Esse manifesto continha ideias vinculadas ao movimento escolanovista ${ }^{11}$. Demonstrar importância em criar um volume com músicas escolhidas pelos alunos continha alguns sentidos contraditórios. As expressões "livre escolha dos alunos", "escolha feita pelo aluno" uma identificação com as propostas do movimento Escola Nova no Brasil, que, em linhas muito gerais, deslocaram o centro de processos educativos no qual o professor é o detentor do saber a ser transmitido, para um outro centro de processo de ensino e aprendizagem: o aluno. Este, em interação com o meio que o rodeia, com o professorado, o alunado e materiais pedagógicos o estimulam a adquirir conhecimentos. Por outro lado, expressões como "músicas selecionadas com o fim de permitir a observação do progresso, da tendência e gosto artístico", indicam, funções de controle sobre o trabalho executado e função de avaliação do estágio de gosto musical, considerado aqui em sua possibilidade evolutiva. É possível que a intenção fosse trazer evidências de que o projeto provocou uma mudança no gosto musical para algo que julgavam ser hierarquicamente superior. Assim, retomando a proposta de Castillo Gómez sobre discursos, práticas e representações da escrita, alguns dados sobre a circulação e apropriação de ideias musicais e nacionalistas expressas nos textos musicais poderiam ser pensados e considerados para a legitimação ou o planejamento de outras etapas do projeto.

A descrição para o $6^{\circ}$. volume (Artístico Musical: música litúrgica e profana, estrangeiras, nacionais e gêneros acessíveis), é compatível para o repertório que Villa-Lobos destinava ao Orfeão dos Professores, no qual incluía peças compostas por ele próprio. Nos fascículos pertencentes à Coleção Escolar, aparece o longo subtítulo: Coleção do Orfeão dos

\footnotetext{
${ }^{10}$ Sobre esse manifesto ver: XAVIER, Libânia Nacif (2002). Para além do campo educacional: um estudo sobre o Manifesto dos Pioneiros da Educação Nova (1932). Bragança Paulista, EDUSF.

${ }^{11}$ Sobre relações entre os signatários do Manifesto dos Pioneiros da Educação e Villa-Lobos, ver: MONTI, Ednardo Monteiro Gonzaga do. Polifonias Políticas e Pedagógicas: Villa-Lobos no Instituto de Educação do Rio de Janeiro na Era Vargas. 2015. 291f. Tese (Doutorado em Educação) - Faculdade de Educação, Universidade do Estado do Rio de Janeiro, Rio de Janeiro, 2015.
} 
Professores, de músicas de vários autores estrangeiros e nacionais, arranjadas, adaptadas e adotadas por H. Villa Lobos. Esse repertório variava em estilos, gêneros musicais e com arranjos de composições de várias épocas na produção musical erudita europeia e brasileira, o que parecia ter como objetivo ilustrar diferentes períodos históricos, pois é possível encontrar temas de Canto Gregoriano, Renascimento, Barroco, Romantismo, e compositores brasileiros como José Maurício Nunes Garcia, Henrique Oswald, Luciano Gallet e Homero Barreto, além de composições do próprio Villa-Lobos (LAGO; BARBOSA; BARBOSA, 2009, p. 44).

O Orfeão dos Professores era constituído por professoras e professores de música das escolas públicas do Rio de Janeiro, que se reuniam para ensaios sob a regência do próprio VillaLobos para prática coral e apresentações musicais em diversos espaços. Para o seleto conjunto de professores que compunha o grupo, participar desse coletivo conferia prestígio e também cumpria uma função de formação continuada, pois esses professores estavam trabalhando repertório especializado e desafiador musicalmente, pelo grau de exigência para a leitura à primeira vista e performance vocal, além de trabalharem peças do repertório destinado às aulas de canto orfeônico e aos grupos orfeônicos que dirigiam em seus locais de trabalho. ${ }^{12}$

Deixamos para o final dessa seção o item do quadro acima que apresenta indicações para $04^{\circ}$. Volume, pois ele nos encaminha, mais especificamente, para foco deste estudo.

Uma forma de identificar a intencionalidade de Villa-Lobos para esse volume é a indicação impressa em alguns fascículos da Coleção Escolar, nos quais aparecem a inscrição “Guia Prático - 4. volume”. É o caso das músicas: Meu Brasil - Samba, Papae Curumiassu, Luar do Sertão. Essas mesmas canções também foram publicadas em Canto orfeônico I e II.

No quadro acima, canções de matriz indígena e africana aparecem em denominação mais explícita com a descrição: Guia Prático $-4^{\circ}$. volume (Folclórico Musical: temas ameríndios, mestiços, africanos, americanos e temas populares universais). Alguns desses termos não são utilizados atualmente. O texto não deixa claro se está sendo considerado apenas manifestações do hemisfério Sul, ou se a música europeia ocidental, estadunidense e a música oriental popular seria incluídas. Ainda que os termos sugiram valorização de diversidades culturais, o projeto dedica apenas um volume para esses tipos de músicas em um total de 6 volumes programados. Há, contudo, que nos deter em alguns aspectos sobre como as organizações de sonoridades foram tratadas nas composições, o que será desenvolvido a seguir.

\footnotetext{
12 Sobre o Orfeão dos Professores de Canto Orfeônico, ver: ROCHA, Inês de Almeida. “O negócio era a voz! Entrevista. Interlúdio: Revista do Departamento de Educação Musical do Colégio Pedro II, Ano 1, n.1, p. 89-98. Rio de Janeiro: Colégio Pedro II, $2010 . \quad$ Disponível em: https://www.cp2.g12.br/ojs/index.php/interludio/article/view/1498/1089.
} 


\section{O GUIA PRÁtico E O ESPAÇO DESTINADO ÀS CANÇÕES DE MATRIZES INDÍGENAS E AFRICANAS}

Alguns títulos são sugestivos e já indicam essa temática pelas palavras utilizadas. Em outras, o título não é muito claro quanto à apropriação de elementos dessas matrizes, porém diferentes elementos musicais e verbais (como as palavras utilizadas da letra das canções), indicam a forma de apropriação dos elementos de matriz indígena e africana. Em ambos casos podemos citar as seguintes canções: Caninde-Ioune-Sabath, Ena-Mokocê-Maka, Teiú, Nozaniná, Papae, Curumiassú, Aboios, Cântico do Pará, Evocação, Cânticos do Çaire 1 a 3, Remeiro do São Francisco, Xangô, Estrela é lua nova e Um canto que saiu das senzalas. Todas essas canções foram músicas publicadas nas demais coletâneas (Coleção Escolar, Canto Orfeônico, Solfejos) e ficaram fora do primeiro volume do Guia Prático, muito provavelmente porque o planejamento seria dedicar um único volume, o de número 4 para essas canções.

É importante destacar que a sintaxe, a estrutura musical das músicas indígenas e africanas é muito diversa da música europeia e os elementos que no período em que foram compostas as identificavam como sendo indígena era a letra da música, intervalos musicais repetitivos e dentre os elementos considerados africanos estava a letra e o ritmo. Outra fonte foram as melodias coletadas em viagens etnográficas, registradas em notação musical de tradição ocidental-europeia (notas musicais, pentagramas, dentre outros símbolos). Destaca-se que essa escrita apresenta limitações e mediação da percepção de quem anota as impressões musicais, não podendo ser considerado como uma cópia fiel do que é executado musicalmente, nem do que é percebido e registrado pelo ouvinte. A possibilidade de interferências, modificações, acréscimos e não registro de aspectos importantes para os que participam da prática musical registrada em um papel por um compositor estrangeiro à essas comunidades, desperta questionamentos sobre as práticas, a circulação e a apropriação de fazeres musicais atribuídos aos indígenas e aos escravos e afrodescendentes.

Por outro lado, há que estar atento às características da música coral do século XX, que tinha, predominantemente, elementos da música hegemônica europeia, tais como a forma musical, a harmonização, o contraponto e a polifonia vocal.

Como recurso composicional, para essas músicas corais foram utilizadas formas, contrapontos vocais e efeitos harmônicos de matriz europeia. A ideologia de uma identidade nacional, que ganhou força no período entre 1937 e 1945, denominado Estado Novo, fomentou a juventude a cantar hinos pátrios, canções militares e muitos temas folclóricos nas escolas. Inúmeras publicações reforçam essa proposta (FUKS, 19991).

Rev. Iberoam. Patrim. Histórico-Educativo, Campinas (SP), v. 6, p. 1-15, e020030, 2020. 
É importante destacar que essas canções não são músicas indígenas ou africanas para serem cantadas nas escolas, mas músicas escritas em estruturas hegemônicas europeia, por pessoas alheias à comunidade indígena e africana ou afrodescendente, aproximando-se dessas diversidades culturas.

\section{CONSIDERAÇÕES FINAIS}

Músicas corais com a indicação canto orfeônico impressa na partitura, no título da obra, no prefácio de coletâneas, ou em outros espaços de partituras, tiveram grande divulgação no repertório coral cantado no Brasil e em outras regiões da Europa e Estados Unidos. Muitas vezes essas músicas são identificadas como representantes da cultura brasileira. Ena-MokocêMaka, Estrela é lua nova, por exemplo, fazem parte do repertório de corais e até a atualidade, em diversos países europeus, dentre eles a Espanha, essas canções são consideradas por muitos músicos, como uma referência de brasilidade. Pessoas que frequentam apresentações corais ou cantam em coros na Europa já passaram pela experiência de cantar e ouvir algumas das canções do Guia Prático, principalmente quando se trata de ressaltar algo caracteristicamente brasileiro que é valorizado no hemisfério Norte.

Villa-Lobos fez uso de melodias e ritmos anotados em viagens etnográficas no interior do Brasil, em diversas composições, inclusive nas canções destinadas ao projeto do Canto Orfeônico que liderou durante muitos anos e que teve o livro Guia Prático como uma de suas publicações mais divulgadas. As músicas corais para uma, duas, três ou quatro vozes femininas, masculinas, infantis ou mistas, representam uma forma de apropriação da música indígena, africana e rural, pelos intervalos melódicos, padrões ritmos e pelas palavras em diversos dialetos, muito embora ainda fortemente marcadas pela música tonal e métrica, pela polifonia coral e melodia acompanhada, tão características da música de povos colonizadores.

As melodias de inspiração indígena, algumas coletadas pelos músicos, trazem uma aproximação à música desses povos, pelos intervalos melódicos, por ritmos, por padrões repetitivos e pelas palavras em diversos dialetos. As canções com matriz africana adotam os mesmos procedimentos composicionais. Partem de anotações em escrita musical disponibilizada em publicações das expedições etnográficas e de anotações pessoais e são transformadas em música coral. A forma, os procedimentos composicionais, de contraponto vocal e os efeitos harmônicos são de matriz europeia e imprimem um cunho predominante à obra. É o que poderíamos aprofundar em uma análise musical mais específica e com referenciais analíticos da música escrita ocidental do século XX em canções como Caninde- 
Ioune-Sabath, Ena-Mokocê-Maka, Teiú, Nozaniná, Papae, Curumiassú, Aboios, Cântico do Pará, Evocação, Cânticos do Çaire 1 a 3, Remeiro do São Francisco, Xangô, Estrela é lua nova, Um canto que saiu das senzalas. Essa análise, entretanto, fugiria ao escopo do presente texto.

Repensar as relações entre colonizadores e colonizados, a partir desse repertório, permite conhecer como a música traduz essas relações em práticas escolares. Mesmo que o discurso valorizado fosse o de que o Brasil só seria brasileiro se direcionasse sua atenção para as culturas mais autóctones, a lógica hierárquica europeia se manteve, descaracterizando as matrizes e as diversidades culturais, reforçando elementos da música clássica ocidental, como foi possível observar na publicação mais emblemática de Heitor Villa-Lobos para seu projeto: O Guia Prático.

O artigo buscou evidenciar como foram realizadas tentativas de diálogo, troca cultural ou valorização da música de grupos sociais que praticavam a música popular rural, indígena e afrodescendentes, sob um viés ideológico nacionalista e modernista de meados do século XX, ainda marcadas pela hegemonia do colonizador e nações detentoras de poder político e econômico. Esse foi o limite alcançado por músicos e artistas modernistas brasileiros, que, mesmo valorizando elementos da música indígena e africana, se apropriavam dessa música elaborando músicas com fortes traços das culturas hegemônicas, herdadas pelo processo colonização. Essas ações, contudo, contribuíram para a constituição de um patrimônio musical e de música para espaços de ensino e aprendizagem. Oxalá pensar em matizes da cultura autóctone ou da diáspora africana, trazendo-as para um primeiro plano, possibilitem outra perspectiva de compreensão da música brasileira e escolarizada. No momento atual, acreditamos que problematizar a forma como compositores produziram, apropriaram e divulgaram a música a ser cantada nas escolas, possa estimular ações no presente e futuro no sentido de repensar nossas referências sobre o patrimônio cultural escolar e as práticas cotidianas educativas com/para/da música.

\section{REFERÊNCIAS}

CASTILlO GÓMEZ, António. Historia de la cultura escrita: ideas para el debate. Revista Brasileira de História da Educação, São Paulo, n. 5, p. 93-124, jan./jun. 2003a.

CASTILLO GÓMEZ, António. Prólogo: Los manuales epistolares: entre el uso y la representación. In: SIERRA BLAS, Verónica. Aprender a escribir cartas: Los manuales epistolares en la España contemporánea (1927-1945). Gijón: Trea, 2003b. p. 13-24. 
CASTILLO GÓMEZ, António. La Corte de Cadmo: apuntes para una historia social de la cultura escrita. Revista de Historiografía, Madrid, n. 1, 2, p. 89-98, 2004.

FUKS, Rosa. O Discurso do silêncio. Rio de Janeiro: Enelivros, 1991.

IGAYARA-SOUZA, Susana Cecilia. Entre palcos e páginas: a produção escrita por mulheres sobre música na história da educação musical no Brasil (1907-1958). Tese (Doutorado em Educação). São Paulo: FEUSP, 2011.

LAGO, Manoel Aranha Corrêa do; BARBOSA, Sérgio; BARBOSA, Maria Clara. Introdução: um guia para o Guia Prático. In: VILLA-LOBOS, Heitor. Guia Prático para a educação artística e musical: separata: primeiro volume: estudo folclórico musical. Manuel Aranha Correa do Lago, Sérgio Barbosa, Maria Clara Barbosa (textos e pesquisa). Rio de Janeiro: ABM: Funarte, 2009.

LE GOFF, Jacques. História e Memória. Tradução: Bernardo Leitão et al. 2. ed. Campinas: UNICAMP, 1992.

MONTI, Ednardo Monteiro Gonzaga do. Polifonias Políticas e Pedagógicas: Villa-Lobos no Instituto de Educação do Rio de Janeiro na Era Vargas. 2015. 291f. Tese (Doutorado em Educação) - Faculdade de Educação, Universidade do Estado do Rio de Janeiro, Rio de Janeiro, 2015.

ROCHA, Inês de Almeida. O negócio era a voz! Entrevista. Interlúdio: Revista do Departamento de Educação Musical do Colégio Pedro II, Rio de Janeiro: Colégio Pedro II, Ano 1, n.1, p. 87-98, 2010. Disponível em https://www.cp2.g12.br/ojs/index.php/interludio/article/view/1498/1089. Acesso em: 3 jan. 2018.

ROCHA, Inês de Almeida. Serve teu Brasil com brio! Cumpre sempre teu dever!: manuais escolares de música no Colégio Pedro II. In: IX CONGRESSO LUSO-BRASILEIRO DE HISTÓRIA DA EDUCAÇÃO, 9., 2012, Lisboa. Anais [...]. Lisboa: Instituto de Educação da Universidade de Lisboa, 2012. p. 5805-5817.

TACUCHIAN, Ricardo. Convergências e Urdiduras. In: VILLA-LOBOS, Heitor. Guia Prático para a educação artística e musical: separata: primeiro volume: estudo folclórico musical. Manuel Aranha Correa do Lago, Sérgio Barbosa, Maria Clara Barbosa (textos e pesquisa). Rio de Janeiro: ABM: Funarte, 2009.

VILLA-LOBOS, Heitor. Canto Orfeônico: marchas, canções e cantos marciais para educação consciente da unidade de movimento. $1^{\circ}$. e $2^{\circ}$. volume. Rio de Janeiro: Casa Arthur Napoleção, 1940.

VILLA-LOBOS, Heitor. Guia Prático: estudo folclórico musical. V. 1. São Paulo, Rio de Janeiro: Irmãos Vitale, 1941.

VILLA-LOBOS, Heitor. Solfejos. $2^{\circ}$. volume. São Paulo: Vitale, 1946. 
VILLA-LOBOS, Heitor. Guia Prático para a educação artística e musical. 1. Volume: estudo folclórico musical / Heitor Villa-Lobos; [textos e pesquisa] por: Manoel Aranha Corrêa do Lago, Sérgio Barboza, Maria Clara Barbosa. Rio de Janeiro: BM; Funarte, 2009.

XAVIER, Libânia Nacif. Para além do campo educacional: um estudo sobre o Manifesto dos Pioneiros da Educação Nova (1932). Bragança Paulista: EDUSF, 2002.

Recebido em: 26 de dezembro de 2020 Aceito em: 30 de dezembro de 2020 